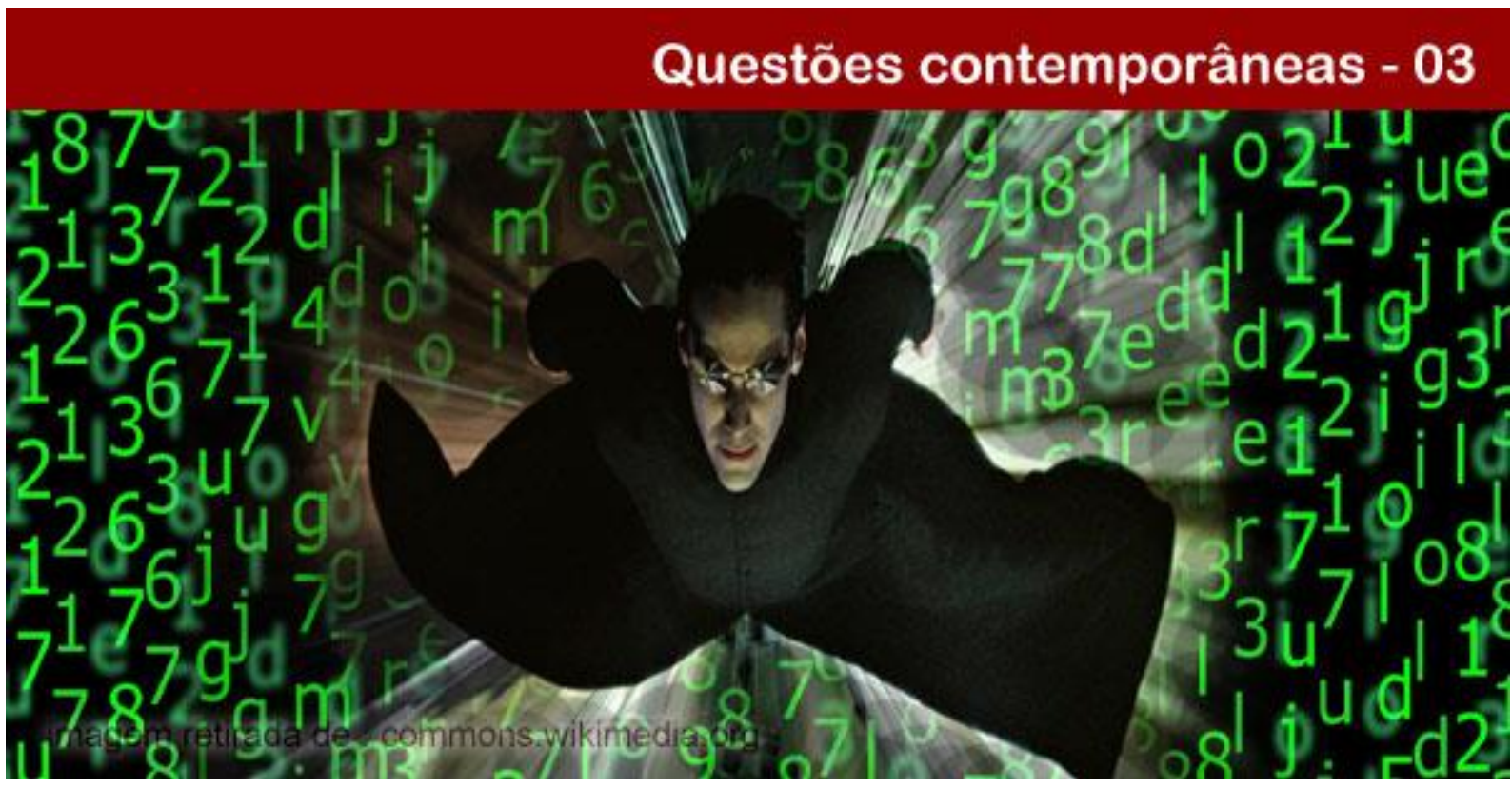

\title{
PENSAR A CONTEMPORANEIDADE DE OUTROS MODOS: CONTRIBUIÇÕES DA PERSPECTIVA FOUCAULTIANA E DELEUZE-GUATTARIANA
}

\section{Clayton Cesar de Oliveira Borges}

Doutorando em Educação e Mestre em Estudos Culturais pela Universidade de São Paulo. Professor de Educação Física da rede estadual paulista. Membro do Grupo de estudos em Pedagogia da Educação Física (GEPEF) da FEFISO Sorocaba. Pesquisador vinculado ao Grupo de Pesquisas em Educação Física escolar da Faculdade de Educação da Universidade de São Paulo (www.gpef.fe.usp.br). E-mail: prof.claytonborges@gmail.com.

\section{Rubens Antonio Gurgel Vieira}

Doutorando em Educação na Faculdade de Educação da Universidade de Campinas (FE/UNICAMP). Mestre em Didática pela Faculdade de Educação da USP. Membro do Grupo de Pesquisas em Educação Física Escolar da Faculdade de Educação da USP e do Grupo de Pesquisa, Linguagem e Práticas Corporais da Faculdade de Educação da Unicamp. Especialista em Docência no Ensino Superior pela Universidade Gama Filho/RJ. Professor da Faculdade de Educação Física de Sorocaba (FEFISO/ACM-Sorocaba). Técnico de Esportes da Prefeitura Municipal de Sorocaba. Formador da Secretaria de Educação da Prefeitura de Sorocaba. Coordenador do Grupo de Estudos em Pedagogia da Educação Física (GEPEF) da FEFISO Sorocaba. E-mail: rubensgurgel@gmail.com.

\section{Vitor de Castro Melo}

Especialista em Educação Física escolar pelo programa de Pós-Graduação da Faculdade de Educação Física da ACM Sorocaba - FEFISO/ACM. Licenciado e Bacharel em Educação Física pela FEFISO/ACM. Integra o Grupo de Estudos em Pedagogia da Educação Física - GEPEF/FEFISO (www.gepeffefiso.blogspot.com) e o Grupo de Pesquisa em Educação Física Escolar - GPEF/FEUSP (www.gpef.fe.usp.br). E-mail: vitormoska@gmail.com

Resumo: Este artigo, inspirado pela filosofia francesa contemporânea e pelos filmes da trilogia Matrix, problematiza alguns questionamentos efetuados pelos paradigmas positivistas em direção aos campos analíticos comumente denominados de pós-moderno e pós-estruturalista. Com certa frequência, estes campos de conhecimento são acusados, entre outros, de relativizarem a verdade, desconsiderarem a objetividade e a exatidão das ciências e, ainda, desacreditarem da razão e do progresso da humanidade. Na tentativa de exercitar

\section{POLÊM!CA $\mid$ LABORE (}

Polêmica - Revista Eletrônica da Uerj - Rua São Francisco Xavier, 524, $1^{\circ}$ andar

bloco D, sl.1001 • Tels.: +55 21 2334-4088/4087 • http://www.e-publicacoes.uerj.br/index.php/polemica/index http://www.labore.uerj.br • laboreuerj@yahoo.com.br 
uma contra-argumentação, a investigação se inicia considerando a problemática das generalizações em relação às expressões pós-moderno e pós-estruturalista, indicando a filiação teórica-metodológica adotada nesse estudo, advinda do pensamento foucaultiano e deleuze-guattariano. Em seguida, se problematiza o alcance da razão cientificista em dar conta da explicação da realidade. Por fim, direciona-se o pensamento às racionalidades políticas contemporâneas, sintetizadas pela oposição binária "direita" e "esquerda".

Palavras-chave: Pós-modernidade. Pós-estruturalismo. Verdade. Realidade. Política.

\title{
THINKING CONTEMPORARY IN OTHER WAYS: CONTRIBUTIONS FROM THE FOUCAULTIAN AND DELEUZE-GUATARIAN PERSPECTIVE
}

\begin{abstract}
This article, inspired by the contemporary French philosophy and the Matrix trilogy films, questions some questions posed by the positivist paradigms towards the analytical fields commonly called postmodern and poststructuralist. These fields of knowledge are often accused, among other things, of relativizing the truth, disregarding the objectivity and accuracy of the sciences, and discrediting the reason and progress of mankind. In an attempt to exercise a counter-argument, the investigation begins considering the problematic of generalizations in relation to postmodern and poststructuralist expressions, indicating the theoreticalmethodological affiliation adopted in this study, derived from foucaultian and deleuze-guattarian thinking. Next, the scope of the scientistic reason in explaining the explanation of the reality is problematized. Finally, the thought is directed to the contemporary political rationalities, synthesized by the binary opposition "right" and "left."
\end{abstract}

Keywords: Postmodernity. Post-structuralism. Truth. Reality. Policy.

\section{Apresentação}

"Eu só posso lhe mostrar a porta, você tem que atravessá-la" - Morpheus (MATRIX, 1999).

Em obras individuais e conjuntas, Deleuze e Guattari apresentam um pensamento original acerca do que se trata filosofar. É comum encontrarmos a concepção que coloca Deleuze como o filósofo e Guattari como o militante, mas para Gallo (2013), certamente há militância em Deleuze e filosofia em Guattari. Qual é, portanto, a grande inovação filosófica proposta pela dupla?

Se partirmos do ponto de vista da impossibilidade de captura do real com exatidão, refutando a ideia de essências nos conhecimentos ou objetos, o mundo cognoscível pode se tornar caótico, perturbador. Para se guiar nas infinitas possibilidades, a filosofia - de acordo com Deleuze e Guattari (1992) - traça planos de imanência que recortam o caos. A partir deste plano, criam-se conceitos que irão operar em problemas específicos, estabelecendo um personagem conceitual. Esta maneira de ver a filosofia é uma ruptura radical com a filosofia clássica grega, da qual a civilização ocidental é profundamente devedora, na qual o objetivo é a contemplação ou a reflexão.

Os planos são compostos por conceitos filosóficos como ato de criação, finalidade última da filosofia. Este plano não é linear, coerente, simples, mas atravessado por múltiplos

\section{POLÊM!CA $\mid$ LABORE}

Polêmica - Revista Eletrônica da Uerj - Rua São Francisco Xavier, 524, $1^{\circ}$ andar

bloco D, sl.1001 • Tels.: +55 21 2334-4088/4087 • http://www.e-publicacoes.uerj.br/index.php/polemica/index

http://www.labore.uerj.br • laboreuerj@yahoo.com.br 
outros planos, com desvios e fraturas, e seus conceitos podem se articular, contrapor, enfrentar ou se aliar a outros conceitos, do mesmo ou de outros planos.

O que este pensamento nos evidencia é menos uma historicidade do pensamento racional, e sim uma localização geográfica dos infinitos planos traçados pelo devir humano. Logo, pensar é tipicamente uma atividade de criação e roubo. Criamos conceitos que irão compor um plano, que será articulado, atravessado, confrontado, unido, fraturado por muitos outros planos compostos por muitos outros conceitos.

Justamente pelo seu caráter criador e ao mesmo tempo transgressor da racionalidade científica moderna, o modus operandi deleuze-guattariano pode ser melhor denominado de procedimento, em detrimento à metodologia. Sua produção pode ser mais bem designada de pensamento, ao invés de conhecimento.

Aos moldes deleuze-guattariano de filosofar, adotamos como personagem conceitual o filme Matrix, entendendo que há potência para o pensamento na série de filmes que se inicia nos anos 1990 e termina na década seguinte. O plano de imanência é a filosofia francesa contemporânea, muitas vezes denominada de pós-estruturalista. Dentro deste plano de imanência, iremos discutir conceitos centrais tendo como objetivo apresentar algumas implicações para a produção do conhecimento e as relações sociopolíticas contemporâneas quando se pensa por este viés.

Na trilogia hollywoodiana Matrix, o protagonista Neo vive como programador de software e hacker na Matrix, uma simulação interativa neural. É convocado, então, por Morpheus, o capitão da embarcação Nabucodonozor e responsável por encontrar o "escolhido", a realizar uma escolha: tomar a pílula azul ou a pílula vermelha. O escolhido em questão é o personagem profetizado que poderá, enfim, libertar os humanos da dominação das máquinas, dotadas de inteligência artificial.

No caso de escolha da primeira pílula, tudo permanece como está, e Neo segue sua vida imerso numa profunda ilusão. No segundo caso, ao escolher a pílula vermelha, a ilusão é dissipada e finalmente o personagem teria acesso "a verdade", qual seja, um mundo pósapocalíptico onde os humanos são "cultivados" dentro de cápsulas, servindo como fonte de bioeletricidade para as máquinas.

A inspiração da película deixa evidente a associação com a filosofia idealista platônica exemplificada na alegoria da caverna. Na esteira deste pensamento clássico, boa parte da

\section{POLÊM!CA $\mid$ LABORE}


filosofia ocidental dá sequência à busca de uma verdade. Mesmo as correntes materialistas, como o marxismo, buscam através de uma "teoria total da sociedade" (SILVA, 2000), a defesa de uma verdade única, na qual o sujeito finalmente acessaria a realidade e a modificaria por meio da "consciência crítica".

Entretanto, a partir de filósofos como Nietzsche, Heidegger e mais recentemente com a filosofia francesa contemporânea com pensadores como Michel Foucault, Gilles Deleuze e Félix Guattari, a questão da verdade única é objeto de crítica, impulsionando pensamentos baseados no perspectivismo. Inspirados por esta vertente filosófica e pela trilogia hollywoodiana, nos debruçamos sobre as perspectivas epistemológicas rotuladas de pósmodernas e pós-estruturalistas, abrindo espaço para pensamentos que colocam em xeque os pressupostos da modernidade.

De modo mais específico, as discussões que intentamos levar a cabo dizem respeito a alguns pontos nevrálgicos da contemporaneidade, pois a concepção de mundo calcada na multiplicidade de perspectivas traz implicações radicais para a organização sócio-política. Problematizaremos, então, as concepções que aludem ao "alcance" da razão para dar conta da realidade. De um lado, aquelas concernentes à suposta objetividade do conhecimento para acesso à realidade, que sofrem questionamentos das perspectivas comumente rotuladas de pós-estruturalistas e, de outro lado, o contra-argumento destas teorias positivistas que intitulam o paradigma sobredito de relativista e irracional.

Também será aqui objeto de discussão alguns dos efeitos da racionalidade econômica oriunda do paradigma moderno no contexto sócio-político, a saber, aquelas intituladas genericamente de políticas de direita e de esquerda. Antes de adentrarmos propriamente a essas questões, delinearemos rapidamente alguns tensionamentos que se dão entre as perspectivas rotuladas de modernas, pós-modernas e pós-estruturalistas.

\section{Modernidade, pós-modernidade, pós-estruturalismo}

"Liberdade, verdade, paz ou talvez amor? São ilusões, fantasias da percepção, sínteses temporárias de um débil intelecto humano tentando desesperadamente explicar uma existência sem significado ou propósito" - Morpheus (MATRIX, 1999).

A discussão é polêmica e antiga: vivemos uma modernidade tardia, uma pósmodernidade ou nunca fomos modernos? De um lado, a crença em um método universal que

\section{POLÊM!CA $\mid$ LABORE}


impulsionou a produção do conhecimento na modernidade, através da razão e da objetividade das ciências. De outro lado, uma oposição que questiona o projeto moderno e busca desqualificar qualquer tipo de positivismo. Esta última perspectiva, comumente denominada como pós-moderna, enquadra no mesmo bojo matrizes teóricas heterogêneas, sobretudo aquelas oriundas das filosofias francesas herdeiras de Nietzsche e seu perspectivismo, cujas publicações ganharam força no último quartel do século XX.

Merece ser realçado que o termo pós-modernismo comporta diversos significados. Inicialmente, a expressão origina-se no campo da arte e se refere, em linhas gerais, a um movimento artístico que pressupõe maior liberdade de criação e de estilos. Em seguida, adentra as ciências humanas e caracteriza-se pela intensa desconfiança com os metarrelatos, que já não dariam conta da explicação do real na época contemporânea, e sua consequente substituição pelos pequenos relatos, conforme aponta o filósofo francês Lyotard (2009), na obra A condição pós-moderna, publicada originalmente em 1979.

Além do pós-modernismo se referir ao movimento artístico e intelectual, o conceito remete ainda a uma temporalidade, isto é, ao período que se seguiu ao fim da segunda guerra mundial. Para explicar a volatilidade e fluidez desse período, além de pós-modernidade, surgem expressões como modernidade tardia, modernidade líquida, hipermodernidade, entre outros. Diante dos distintos significados que cada um desses conceitos expressa, qualquer tentativa de fixação ou generalização do termo pós-modernismo pode ser uma atividade intelectual, no mínimo, arriscada.

Sem muitas vezes se atentar para as diferenças e singularidades, importantes obras de autores como Foucault, Derrida, Deleuze, Guattari, entre outros, servem de esteio para o discurso rotulado de pós-moderno, em sua vertente ou utilização filosófica, isto é, enquanto movimento intelectual que questiona o paradigma moderno. É preciso dizer, contudo, que estes teóricos mencionados nas linhas acima nunca se posicionaram como pós-modernos, e recusavam com frequência qualquer tipo de enquadramento das suas produções.

Assim, se nos valemos aqui dos conceitos de moderno e pós-moderno, é preciso considerar as devidas ressalvas que estas noções requerem, sobretudo a caracterização de pósmoderno - que procede a uma generalização digna de ser colocada em suspenso. Diante disso, ao invés de recorrer a tal generalização, ainda que inegavelmente possua efeitos didáticos interessantes, optamos aqui por problematizar algumas questões para adentrar o debate.

\section{POLÊM!CA $\mid$ LABORE}


Em um pequeno, mas instigante texto, cujo título tem o formato de pergunta: Um debate (im)possível?, Veiga-Neto (1996, p. 3) enuncia que o debate entre o pensamento moderno e o pós-moderno, ao menos em termos estritos, seria impraticável, porque são orientados por epistemologias distintas e, portanto, inexequíveis: "não há um tribunal epistemológico que sirva igualmente para falarmos de um ou de outro e, mais importante, para decidirmos qual é melhor".

Entretanto, a impossibilidade de diálogo em termos estritos não impediria o debate em termos latos, "desde que não se estruture, por exemplo, em torno de um elenco de categorias modernas (razão, sujeito, liberdade, consciência, etc.) a favor e contra as quais os grupos debateriam" (VEIGA-NETO, 1996, p. 5, grifos do autor). Dito de outro modo, a perspectiva caracterizada como pós-moderna não coaduna com a ideia de um debate fundado em uma "racionalidade dura", que resolveria de uma vez por todas a disputa.

Talvez a argumentação mais perspicaz pontuada pelo autor em um eventual debate entre modernos e pós-modernos, diga respeito a uma questão correntemente enaltecida pelos pós-modernos e que, no entanto, poderia se voltar contra eles próprios: "se esse paradigma se caracteriza pelo elogio da diferença, pela pluralidade da razão, como vou justificar uma tentativa de demolir outras perspectivas só porque diferem da minha?" (VEIGA-NETO, 1996, p. 6).

Diante de tal entrave, isto é, a inviabilidade de um debate pautado em pressupostos que em sua maioria são diametralmente opostos, restaria como alternativa a cada grupo apresentar o modo como se pensa. Um trabalho, portanto, de convencimento, ou de propaganda, se quisermos. Outra possibilidade consistiria em evidenciar as fragilidades e imprecisões de cada paradigma, tarefa nada trivial na medida em que cada referencial busca camuflar suas próprias inconsistências.

Se o conceito de pós-modernismo é problemático, a ideia de um movimento intelectual denominado de pós-estruturalista segue a mesma lógica. Peters (2000) esclarece que os termos pós-modernismo e pós-estruturalismo remetem a campos conceituais distintos, com objetos de estudo diferenciados.

O primeiro trata de um tempo histórico, abrangendo todos os campos do conhecimento, o segundo trata da continuidade e concomitante ruptura com um movimento intelectual específico denominado estruturalismo. O conceito de pós-modernidade, diante da

\section{POLÊM!CA $\mid$ LABORE}


diversidade de posições, com frequência declara guerra a princípios universais, metanarrativas, verdades absolutas, favorecimento do perspectivismo; já o conceito de pósestruturalismo refere-se a uma radicalização da perspectiva estruturalista e é frequentemente melhor entendido a partir da obra de autores tidos como expoentes.

Em linhas gerais, estruturalismo é um movimento das ciências humanas iniciado com a linguística de Saussure, que oferece um modelo de compreensão da realidade a partir de uma estrutura formal constante e passível de ser pesquisada em todo o tecido social. Saussure identificou a linguagem como uma estrutura a partir da cadeia de significados gerados a partir de significantes correspondentes.

A análise de estruturas foi utilizada na Antropologia por Lévi-Strauss, na psicanálise por Lacan e muitos outros, se tornando um movimento francês com muita influência no mundo intelectual. Nesse contexto, se destacam os trabalhos arqueológicos de Foucault, que se iniciam com a obra A História da Loucura, de 1961, frequentemente definidos como investigações estruturalistas - alcunha que o filósofo francês recusou de forma veemente, chegando à ironia e ao cômico nas falas de refutação.

Pós-estruturalismo, ao contrário de outras perspectivas, não é um movimento com contornos tão bem definidos e consenso acadêmico, e provoca reações acaloradas, assim como o conceito de pós-modernismo. Gallo, por exemplo, afirma:

\footnotetext{
Discordo abertamente, portanto, daqueles que se apressam em falar em "pósestruturalismo" ou em abarcar quase tudo sob o epíteto de "pós-modernismo". De um lado porque o prefixo "pós' designa apenas uma posterioridade temporal e aí caímos na obviedade: claro que absolutamente tudo o que foi produzido posteriormente ao estruturalismo é 'pós-estruturalismo', mas isso é muito pouco para delimitar um esforço de pensamento e produção conceitual; de outro lado porque o pós-modernismo, se é que podemos, de fato, falar em algo assim, seria também um termo excessivamente vago para designar esforços de pensamento (GALLO, 2013, p. 27).
}

Diante do exposto, é de se questionar fortemente qualquer trabalho que se apoie em uma teoria "pós-estruturalista" sem especificar o que exatamente está afirmando. Para não incorrer em tal ato, recorremos aos escritos de Williams (2012), para quem o movimento entendido como pós-estruturalista só pode ser entendido a partir de uma análise profunda da obra de autores que possuem modus operandi com certa identificação.

Williams (2012) estuda o que há em comum em autores como Foucault, Derrida, Deleuze, Rorty e Kristeva. Para ele, há conceitos chave que os unem, sendo o denominador

\section{POLÊM!CA $\mid$ LABORE}


comum a ideia que os limites do conhecimento têm um papel inevitável em seu âmago. Se o movimento estruturalista busca ilhas de conhecimento seguro ao envolver diferenças em estruturas rígidas, ir além é reconhecer a função desestabilizadora dos limites irregulares desta estrutura. Ao mudar a ênfase, o limite é o cerne, não por oposição ao âmago, mas positivo por si.

Não se trata, entretanto, de centralizar o limite, ele não pode ser identificado. A diferença é algo que não pode ser apreendido, exceto no seu momento de surgimento e transformação do centro. Ser pós-estruturalista, na visão de Williams, é rastrear os efeitos da diferença, do limite. Uma vez que depende de contexto para ter sentido e possibilitar a irrupção da diferença, estudos pós-estruturalistas são sempre aplicações práticas sobre o conhecimento do interior, demonstrando suas exclusões, naturalizações, arbitrariedades, construções reguladas por operações de poder.

Segundo Williams (2012), um dos autores cujos escritos parecem alinhados ao pósestruturalismo é o filósofo francês Derrida. A filosofia pós-estruturalista de Derrida remete aos aspectos arbitrários da linguagem, apontando que a naturalização que envolve signo e significados é fruto de disputas socioculturais. Desta forma, mesmo sendo movimentos distintos, com discordâncias internas e com nomenclaturas generalizantes contestadas por muitos autores que promoveram seus avanços, ambos possuem interseções e terreno fértil ao pensar.

Abordar a linguagem sob a ótica pós-estruturalista derridiana significa entender o signo (conceito de algo) enquanto algo separado do significado e significante (aquele que estipula o significado) e, mais, que a relação entre eles é arbitrária, construída, temporária, finita, limitada e contestada.

Em outras palavras, a partir da utilização da linguagem, a conceituação do mundo mudará de indivíduo para indivíduo, num sentido mais particular, e de cultura para cultura em um sentido mais "macro" - ou, no que nos interessa aqui, múltiplas visões de mundo. Desta forma, se um significado foi construído socialmente, ele é passivo de ser desconstruído, desfazendo a conexão entre significado e significante, apontando as conexões de poder que naturalizaram determinados contextos sociais.

Voltando à perspectiva teórica rotulada de pós-moderna, vale dizer que os questionamentos que Foucault efetua a respeito de conceitos caros à modernidade, entre eles,

\section{POLÊM!CA $\mid$ LABORE}


o predomínio do conhecimento científico na produção dos saberes e, ainda, a concepção essencialista de sujeito enquanto base e fundamento da ação, não se devem ao fato de pretender ser pós-moderno, mas problematizar, manter uma "atitude crítica" (FOUCAULT, 2005) a respeito dos efeitos de verdade que tais processos produziram e, ao que tudo indica, continuam produzindo.

As raras vezes em que Foucault se referiu ao termo pós-moderno foi para recusá-lo, apontando os equívocos de tomá-lo como um pensador pós-moderno. Vejamos uma passagem em que o filósofo retoma a questão kantiana sobre o que seriam as Luzes:

Sei que se fala frequentemente da modernidade como uma época ou, em todo caso, como um conjunto de traços característicos de uma época; ela é situada em um calendário, no qual seria precedida de uma pré-modernidade, mais ou menos ingênua ou arcaica, e seguida de uma enigmática e inquietante pós-modernidade [...] mais do que querer distinguir o "período moderno" das épocas "pré" ou "pós" modernas, creio que seria melhor procurar entender como a atitude de modernidade, desde que se formou, pôs-se em luta com as atitudes de "contramodernidade" (FOUCAULT, 2005, p. 341-342).

Além de refutar a expressão pós-modernidade, Foucault descarta a ideia de que haveria uma ruptura radical ou um suposto progresso entre as temporalidades mencionadas acima. Isso não significa, entretanto, que não tenham ocorrido descontinuidades em determinadas épocas, aliás, questão que o filósofo tão bem explicitou em suas inúmeras pesquisas históricas, quando recorre ao período greco-romano, ao cristianismo primitivo, ao renascimento, à época clássica ${ }^{1}$ e à modernidade.

A preocupação central de Foucault, mesmo quando recorre a épocas tão remotas, é melhor compreender a contemporaneidade. Suas investigações consistem em uma reflexão, uma atitude crítica sobre o presente. Operar criticamente, para o filósofo, se afasta de uma ideia de crítica enquanto polêmica, como é bastante comum no embate entre perspectivas epistemológicas que possuem concepções distintas. A crítica, em Foucault, atua no interior do próprio pensamento, e possui função retrospectiva, isto é, busca compreender o porquê fazemos o que fazemos; não se trata, portanto, de modo algum, de disputar qual conhecimento é o "mais verdadeiro".

Assim como podemos perceber os embates epistemológicos travados acerca de uma leitura de mundo, na película, este embate é personificado nos personagens do agente Smith e

\footnotetext{
${ }^{1}$ A noção de época clássica na obra de Foucault se refere tanto aos séculos XVII e XVIII, que é o sentido empregado aqui, quanto ao período clássico da cultura ocidental grega, entre os séculos V a. C. e III a. C.
}

\section{POLÊM!CA $\mid$ LABORE}


do Neo. Em um jogo de significações que atravessa a trilogia, somos levados a problematizar a própria busca de uma verdade que rege as condutas de ambos os personagens.

No primeiro filme, o agente Smith se apoia no discurso da razão para conduzir suas ações frente ao embate com Neo. Mas, no decorrer da trilogia, suas certezas são abaladas frente a cada desconstrução proposta pelo seu antagonista. Ao final do primeiro filme, Neo derrota seu oponente em uma demonstração de liquidez das fronteiras discursivas da física, da química e da biologia. Seu personagem se "funde" ao agente Smith e o derrota explodindo seu corpo de dentro para fora.

No retorno do personagem, no decorrer do segundo filme da trilogia, sua narrativa e leitura de mundo são alteradas, pois, segundo o personagem, seu desligamento do sistema lhe transformou em um novo homem.

Sr. Anderson [Neo], surpreso em me ver? Então, tem consciência da nossa ligação. Não entendo bem como aconteceu. Talvez uma parte de você inserida em mim, algo sobrescrito ou copiado. Agora é irrelevante. O que importa é que o que aconteceu teve um motivo. Eu matei você. Vi você morrer com certa satisfação, devo dizer. Aí, algo aconteceu, algo que eu sabia que era impossível, mas que aconteceu assim mesmo. O Senhor me destruiu, Sr. Anderson. Depois disso, eu sabia as regras, entendia o que deveria fazer, mas não fiz. Não consegui. Fui compelido a ficar... compelido a desobedecer. E agora aqui estou, por sua causa, Sr. Anderson. Por sua causa, não sou mais agente do sistema. Por sua causa, mudei, estou desconectado. Um novo homem, por assim dizer". Agente Smith (MATRIX RELOADED, 2003).

\section{A realidade}

\footnotetext{
"O que é real? Como você define o 'real'? Se você está falando sobre o que você pode sentir, o que você pode cheirar, o que você pode saborear e ver, o real são simplesmente sinais elétricos interpretados pelo seu cérebro" - Morpheus (MATRIX, 1999).
}

Segundo Hicks (2011), todo pensamento sistematizado comporta uma metafísica, ou seja, uma explicação sobre o que é o real e, a partir do caminho escolhido, advém conceitos que se articulam e formam uma teoria - ou melhor, discurso - sobre a vida.

A herança iluminista, ancorada no potencial da razão como guia da humanidade, prega que o ser humano possui em seu intelecto o aparato que precisa para manipular a realidade. Assim, a racionalidade científica moderna permite uma objetividade transformadora da realidade circunscrita. Não por acaso, o pensamento moderno utilizou inúmeras teorias, concepções científicas, filosóficas, com o intuito de transformação da realidade pautada em conhecimentos provenientes da razão.

\section{POLÊM!CA $\mid$ LABORE}


Voltemos à analogia com o filme: na trilogia, Neo é convencido por um grupo de pessoas que ele é o "escolhido", aos moldes cristãos. A humanidade foi subjugada por máquinas que adquiriram consciência e poucos rebeldes sobrevivem escondidos em cavernas profundas.

Antes da derrocada, a humanidade consegue destruir o Sol, fonte de calor e energia infinita para as máquinas todo-poderosas. O estratagema levou as máquinas a escravizarem os seres humanos para serem transformados em fonte de obtenção de calor, presos a cilindros bioelétricos por toda a vida. $\mathrm{Na}$ introdução de tal processo, as máquinas dominantes constatam que a vida de um ser humano era abreviada em estado de cativeiro, pois violentava sua necessidade de ser social.

Para resolver a questão, os escravagistas mecânicos criam um programa de computador, denominado Matrix, que "rodava" na consciência dos escravos uma cópia do mundo humano em seu auge, o século $\mathrm{XX}$, anterior à rebelião/revolução que dizimaria a humanidade. O objetivo dos humanos rebeldes restantes, então, é detectar pessoas que conseguem resistir ao mundo criado pela Matrix, convencê-las a sair do software através das pílulas, e resgatá-las fisicamente para encorpar as linhas defensivas com táticas de guerrilha. Ou seja, os rebeldes funcionam como verdadeiros vírus de computador.

Há uma objetividade e uma verdade a ser descoberta, basta para isso empreender métodos adequados, sistemáticos, não há espaço para dúvidas. A ciência, fruto da modernidade, opera na mesma racionalidade. O pensamento moderno acredita na objetividade e gasta seus esforços na descrição de regularidades, na busca por positividade, por explicações universais e totalizantes, em verdades inquestionáveis, mesmo que provisórias, pois o progresso é teleológico.

No pensamento aqui convencionado como pós-moderno, que segundo Hicks (2011), se inicia com o filósofo moderno por excelência Immanuel Kant, na obra Crítica da Razão Pura, de 1781, a realidade é inacessível em sua completude, pois dependemos dos sentidos como via obrigatória de acesso ao real, relegando à razão a função de trabalhar com informações de "segunda mão".

Entretanto, Kant não tencionava diminuir a importância da razão, mas sim abrir espaço para uma posição religiosa dentro do crescente pensamento iluminista - pensamento que colocava a razão acima de qualquer forma de conhecimento. Uma vez que não é possível

\section{POLÊM!CA $\mid$ LABORE}


saber com exatidão o que é o real, critica-se não a existência da realidade independente da percepção humana, mas a capacidade da razão de dar conta da complexidade do real.

Indo além da questão sensitiva, a partir do século XX ocorre o que Hall (1997) denomina de "virada linguística". Neste movimento, centraliza-se nas análises filosóficas a questão da construção social dos significados cujo acesso se dá, sobretudo, por meio dos órgãos dos sentidos. A virada linguística é uma revolução nas ciências humanas proporcionada inicialmente pelo movimento estruturalista, discutido acima, e radicalizada pela teoria da desconstrução derridiana.

Diante da constatação de que alguns conhecimentos possuem maior regularidade com a realidade do que outros, como, por exemplo, as ciências exatas, na visão pós-moderna enfatizam-se os aspectos arbitrários da construção sociocultural. Desta forma, mesmo as ciências exatas encontram seus limites, o que deixa evidente os limites da razão.

Entretanto, ao contrário do que afirma Hicks (2011), isso não significa defender o relativismo em termos absolutos, no sentido de "vale qualquer coisa", mas tão somente ponderar que os diversos conhecimentos estão sempre ancorados num contexto sócio histórico e envolvidos em relações de poder. Dito de outro modo, o que é definido como real depende, fundamentalmente, de um saber específico, de uma discursividade arbitrária sobre o que é a realidade. Em suma, a realidade é fabricada, politicamente construída.

Em suas pesquisas arqueológicas, examinando as epistemes de um período de aproximadamente cinco séculos, qual seja, do renascimento à modernidade, Foucault (2000) destacou as diversas rupturas, transformações e descontinuidades dos saberes históricos sobre os quais se deteve, nos campos respectivos em que surgiram os saberes da vida, do trabalho e da linguagem.

Depreende-se disso a suspensão de qualquer sentido transcendental ao saber, de modo que a verdade e, por conseguinte, a realidade, são arquitetadas e incidem de modo distinto sobre os sujeitos a elas atrelados, em acordo com o contexto cultural de uma época.

Certamente, algumas objeções poderão ser feitas a essas investigações levadas a cabo por Foucault, pretensamente pela ausência de uma cientificidade hard, já que são relativas às ciências do homem, consideradas frágeis em demasia, por não se fundamentarem em um procedimento lógico-dedutivo.

\section{POLÊM!CA $\mid$ LABORE}


Ora, a esse respeito, podemos recorrer, entre tantos outros exemplos, à teoria da incompletude formulada pelo lógico vienense Kurt Godel, de 1931, em que o pesquisador coloca sob suspeita algumas asserções matemáticas, enfatizando a incapacidade desse campo de conhecimento em demonstrar sua própria consistência lógica.

Godel demonstrou a insuficiência lógica para afirmar a veracidade ou a falsidade de inserções matemáticas simples. Por exemplo: "Pela lógica, não é possível demonstrar que essa hipótese é verdadeira”. Se a proposição acima for verdadeira, então vale a afirmação que é impossível demonstrá-la verdadeira. Se a proposição for falsa, vale a inversão da afirmação e, portanto, é possível demonstrar que ela é verdadeira. Gera-se assim, de qualquer modo, uma contradição lógica (SANCHOTENE, 2015, p. 62).

As teorias modernas apostam alto no poder de organização conceitual racional, ignorando aspectos irracionais, imprevisíveis, complexos, sensíveis (CONNOR, 1996). Na crítica da modernidade destacada em Nietzsche e seus herdeiros, mas iniciada por Kant, somos fruto de uma exacerbação racional que despreza uma característica básica do pensamento humano: todas as ideias se originam no sensível, e boa parte delas não passa pela razão.

Se a razão é um "farol” que ilumina muito pouco, a questão sobre como se dá o controle deste farol é anterior às potencialidades da razão. Neste sentido, as criações racionais estão em igualdade de condição, todas as respostas e tentativas igualmente viáveis, sem um corte racional que justifique o reino de uma sobre as outras.

Dessa perspectiva, as escolhas teóricas, científicas e, por consequência, políticas, sociais e educacionais são muito mais fruto de um ethos, enquanto atitude crítica sobre nós mesmos (FOUCAULT, 2005), do que uma necessidade a priori, ou seja, se não há imperativos universais, toda e qualquer criação teórica sofre do mesmo mal: sua provisoriedade, fragilidade ante a complexidade, seu processo degenerativo e entrópico, a impossibilidade de transcendência. Ao negar tais condições, um conjunto de ideias passa de proposição criativa para uma imposição totalitária, correndo riscos de provocar efeitos destrutivos.

Como já enfatizamos, cautelas quanto ao relativismo necessitam ser levadas em consideração. Se a razão é insuficiente para darmos conta do que é entendido como realidade, sem ela tampouco temos ferramentas suficientes para propor qualquer criação. Se a inspiração

\section{POLÊM!CA $\mid$ LABORE}


vem do caos (DELEUZE; GUATTARI, 1992), a organização vem da sistematização propositiva.

Tendo em vista que a compreensão plena dos processos de realidade é impossível, não se pode negar que alguns fenômenos possuem regularidade suficiente para que alguns conhecimentos com maior empiria possam ser gerados. São ferramentas de transformar pequenas realidades contextuais que, sob o aspecto de um rigoroso processo de veridicção, dão margem para a fé cega moderna na objetividade controladora.

Se por um lado, a elevação de tais ferramentas a bussola ética humana têm causado enormes dificuldades à civilização contemporânea, por outro lado, a vida sem elas igualmente seria dificultada. Com isto, busca-se afirmar que não se trata de cair na armadilha relativista, onde se ignora efeitos materiais perceptíveis em favorecimento de malabarismos linguísticos maquiavélicos.

Para deixar claro: para o ser humano, o elo entre as percepções, o pensamento, as ideias e o real é a linguagem. Mediamos nosso pensar e a materialidade com diversas formas de comunicação compreendidas no conceito de linguagem. Levando em consideração que as línguas são criações humanas para potencializar a vida, não podemos ignorar seu poder performativo (HALL, 1997).

Se não há nada de concreto e natural nesta ferramenta, ou seja, se não há correspondência direta entre o pensamento, a linguagem e a materialidade, fica difícil advogar verdades universais, morais transcendentes, valores únicos. Se, por um lado, há o risco da imposição totalitária, por outro lado, há o risco das imposições linguísticas, o uso antecipado da arbitrariedade dos signos como arma linguística desonesta.

O paralelo com os filmes finalmente se completa. Ao fim do terceiro episódio, Neo já se encontra livre da ilusão Matrix, e quando opera por dentro dela é sempre para sabotar o programa das máquinas e seus planos, sempre com uma capacidade de processamento de dados muito acima dos outros rebeldes colegas, afinal ele é The One, o escolhido.

$\mathrm{Na}$ reta final do filme, no plano objetivo da vida "real", Neo e seus colegas são encurralados por máquinas de guerra e, quando estão prestes a sucumbir, o herói usa poderes inexplicáveis para desligar todas as ofensividades.

Como ele faz isso? Com a força do pensamento? Alguma conectividade resultante da sua ligação prévia? Uma força mística? Qualidades sobrenaturais do corpo de Neo? Nada

\section{POLÊM!CA $\mid$ LABORE}


disso é explicado ao fim da história. O roteiro das irmãs Wachowski é construído de tal forma que a explicação, se houver alguma, cabe inteiramente à perspectiva do expectador - bem aos moldes pós-estruturalistas.

A trilogia Matrix expõe assim a relação com o perspectivismo, se apresentando em seu caráter anti-universalista, contrário a metanarrativas, a verdades únicas, sempre se apoiando em múltiplas perspectivas. Se até o primeiro filme da trilogia o discurso estava alinhado a uma perspectiva da modernidade, ou seja, herança direta de um platonismo largamente difundido pelos filósofos do Iluminismo, ampliado e sedimentado pela filosofia cartesiana, na sequência final do último filme a conexão moderna é implodida e não há fechamento do significado em torno de uma verdade.

Desta forma, defendemos que a conclusão da ficção cinematográfica é profundamente imbricada com pressupostos da filosofia francesa contemporânea, e serve como um personagem conceitual dentro do plano traçado. Na sequência, discutimos algumas implicações políticas de ver o mundo como uma multiplicidade heterogênea e o conhecimento como criação perspectiva.

\section{A política}

"Esperança, eis a quintessência do delírio humano ao mesmo tempo fonte de sua maior força e de sua maior fraqueza" - Arquiteto (MATRIX RELOADED, 2003).

$\mathrm{Na}$ esfera da política, mais especificamente da política econômica, há um intenso debate e troca de acusações entre, de um lado, uma hegemônica racionalidade neoliberal e, de outro, correntes teóricas neomarxistas ${ }^{2}$ que possuem certa força acadêmica, mas pouca representatividade política. Não são raras as acusações advindas desses últimos grupos em relação ao pensamento caracterizado como pós-moderno e/ou pós-estruturalista que, conforme argumentam, além de fragmentar as lutas por demandas sociais, contribuem para a manutenção ou reforço do neoliberalismo.

Apesar do enfraquecimento do pensamento marxista no que concerne à ação política contemporânea, resultando em deslocamentos da ideia de revolução via sindicalismo

\footnotetext{
${ }^{2}$ Conjunto das correntes nascidas nos anos vinte do século XX, em torno das teses de György Luckács (18851972), Karl Korsch (1896-1961), Ernst Bloch (1885-1977) e Antonio Gramsci (1891-1937).
}

\section{POLÊM!CA $\mid$ LABORE}


partidário, alguns grupos ortodoxos ainda mantêm esse ideal e refutam veementemente qualquer alternativa.

Em linhas gerais, a proposta desses grupos é a seguinte: a tomada do poder do Estado e dos meios de produção para a implantação de uma nova sociedade deve partir do partido revolucionário e seus intelectuais, cabendo aos militantes tão somente praticar a obediência, tendo em vista que o ideal coletivo se sobrepõe ao individual.

Afastados do proselitismo marxista, irromperam inúmeros movimentos sociais (feministas, negros, gays, antiprisionais) no jogo político da sociedade contemporânea, tendo como marco significativo as manifestações políticas de Maio de 1968, que como bem sabemos ocorreram à revelia dos ditames dos partidos revolucionários "tradicionais".

Essas manifestações evidenciaram e continuam a evidenciar novas formas de luta, que objetivam a insubmissão de condutas preconcebidas e, por conseguinte, a liberação das subjetividades (FOUCAULT, 2004). Ao que tudo indica, alguns grupos marxistas desconsideram a positividade e efeitos desses movimentos.

Certamente, algumas análises de viés marxistas relativas às formas de desigualdade econômica que caracterizam a sociedade capitalista e, ainda, os efeitos da racionalidade neoliberal são potentes para problematizar um aspecto específico, a despeito da exaltação a um tipo de "análise total" da sociedade, unicamente através da via econômica, conforme pleiteiam. Dessa perspectiva, toda a análise que não segue a lógica marxista é prontamente refutada e enquadrada às vezes em tom de deboche como pós-moderna ou neoliberal, como se fossem sinônimos.

Para exemplificar, alguns consideram Foucault como um pensador alinhado ao neoliberalismo, sobretudo pela constante "desconfiança" e questionamento que este apresenta em relação ao Estado e, também, por conta de seus escritos sobre o liberalismo que resultaram na obra $O$ nascimento da biopolítica.

Uma das abordagens que buscam associar o filósofo ao neoliberalismo se deve ao interesse dele pelo deuxième gauche, a esquerda radical francesa, e sua inclinação autogestionária que, supostamente, se alinharia com os ideais neoliberais de empreendedorismo.

No artigo Foucault e racionalidade (neo)liberal, Avelino (2016) atesta as inconsistências da associação entre o neoliberalismo econômico e o deuxième gauche,

\section{POLÊM!CA $\mid$ LABORE}


enfatizando que a autogestão deste último em nada se aproximaria aos ideais de lucro, já que o propósito fundamental seria destruir o monopólio de classe e, ainda, transformar as estruturas das empresas e a relação entre os homens. O autor dirá, então, que, ao contrário de uma conexão aos ideais neoliberais, haveria uma "tentação anárquica no contexto político da deuxième gauche francesa" (p. 235).

Outra tentativa de associação de Foucault ao pensamento neoliberal advém, segundo Avelino (2016), da crítica que o filósofo efetua ao excessivo governamento empreendido pelas sociedades disciplinares. Ora, se o neoliberalismo pleiteia a não intervenção do Estado e, portanto, menos governo, está feita a conexão.

De modo surpreendente, até mesmo a noção foucaultiana de cuidado de si (ephiméleia heautoû), que remete às práticas de si do período greco-romano e que objetivam a criação de novos modos de ser e de viver, será associada aos conceitos neoliberais de liberdade individual, que visa fundamentalmente o investimento econômico em si mesmo.

Distante tanto de uma abordagem ideológica, quanto de denúncia, a atitude de Foucault em relação ao liberalismo foi tão somente descritiva e analítica (AVELINO, 2016). Em outros termos, o intuito foi examinar sua racionalidade política, isto é, por intermédio de quais estratégias e instrumentais essa forma de governo pôde operar. É dessa perspectiva que Foucault descreve o modus operandi ou racionalidades do liberalismo, a saber, a razão do Estado, o poder pastoral e o biopoder.

No que tange às críticas oriundas de teóricos socialistas em relação à opção do filósofo francês pela análise do liberalismo econômico, o próprio Foucault (2008) aponta que o socialismo, embora tenha um extenso corpus teórico, não possui uma arte de governar própria e foi esse o motivo precípuo pelo qual ele analisou o liberalismo econômico.

Analisando o curso Governo de si e dos outros, Gros (2010) assevera que a desconfiança de Foucault em relação ao socialismo advém, entre outros, do governo socialista francês de François Miterrand, do início da década de 1980; na ótica do filósofo francês, este tão somente se basearia em um prolongamento das técnicas de governo, oriundas de governos franceses de direita anteriores.

Foucault assevera, portanto, que a racionalidade econômica está presente tanto em governos liberais quanto naqueles que se alinham aos ideais socialistas. Nesse aspecto, talvez as políticas econômicas contemporâneas dos países nórdicos possam ser um exemplo no

\section{POLÊM!CA $\mid$ LABORE}


mínimo curioso, pois devido aos efeitos considerados "positivos" das políticas econômicas desse conjunto de países, são "adotadas", "acolhidas" por ambos os grupos, ou seja, enquadradas como políticas de bem-estar social pelos grupos socialistas e como políticas neoliberais, obviamente, por pensadores alinhados a esta racionalidade econômica.

Em que pesem as diferenças conceituais em jogo, o pensamento de Deleuze (1989) sobre governo de direita e de esquerda é interessante em relação a essa problemática. Em uma conhecida entrevista concedida para Claire Parnet, intitulada $O$ que é ser de esquerda?, e que juntamente com dezenas de outras questões resultou no documentário O Abecedário de Gilles Deleuze, o autor sustenta a ideia de que não existe de modo stricto sensu um governo de esquerda.

Não se trata, contudo, de afirmar a ausência de diferenças entre governos, mas, no limite, o que teríamos seria um governo que atenderia algumas demandas do pensamento enquadrado como esquerda - o que, convenhamos, não é pouca coisa no contexto atual -; desse ângulo, ser de esquerda é uma questão de "percepção", um modo de apreender o mundo e, ainda, de "ser ou devir minoria".

Dentro de um exercício um tanto simplório de pensar, podemos estabelecer ainda uma analogia com os recentes governos brasileiros que se descreviam como de esquerda, entretanto, o posicionamento nas principais questões era alinhado à governamentalidade neoliberal, no que pese alguns programas sociais nunca antes realizados.

Em relação à intensa troca de acusações tanto de um lado (direita) quanto de outro (esquerda) sobre os efeitos históricos de tais políticas, que resultaram, como bem sabemos, em totalitarismos, hiperadministração estatal, judicialização da vida por meio de uma governamentalidade biopolítica e tecnologias de segurança que, parafraseando Agamben (2005) em A política da profanação, atuam não na manutenção da ordem, mas na regulação e gestão da desordem, podemos inferir que não se trata de "optarmos" por um lado ou outro, mas de desanuviarmos o olhar binário.

Em consonância com o posicionamento de constante desconfiança requerido na perspectiva aqui adotada, percebemos a generalização que, sob o pano de fundo de um paradigma de Estado de Direito, nos subjetiva a crer na possibilidade de uma sociedade justa frente à dicotomia que se faz presente em tal discussão.

\section{POLÊM!CA $\mid$ LABORE}


Segundo o filósofo italiano Agamben (2005), "o verdadeiro ponto misterioso da política ocidental não é o Estado, não é a Constituição, não é a soberania, mas o governo. Não o soberano, mas o ministro. Não o legislador, mas o funcionário ${ }^{3 \%}$.

Dessa perspectiva, não por acaso Foucault (2002, p. 22) inverte o aforismo de Clausewitz ${ }^{4}$ dizendo que mesmo no interior da "paz civil", "a política é a guerra continuada por outros meios", porque esta prioriza a guerra infindável contra as possíveis ameaças internas à sociedade, tornando cada cidadão um inimigo em potencial.

Numa época em que figuram como "líderes" de Estado sujeitos como Kim Jon-um, Vladimir Putin, Bashar al-Assad, Donald Trump, Michel Temer, entre tantos outros, tal enunciação é, no mínimo, de uma atualidade impressionante.

Em suma, historicamente temos assistido desigualdades de todas as ordens e uma infinidade de mortes resultante de guerras, conflitos sociais e econômicos. Portanto, compreendemos que se trata de um debate complexo e problemático, já que diante de tais acontecimentos é extremamente dificultoso, senão impossível, fazer menção a qualquer positividade aos binarismos políticos, ao menos em sentido amplo.

Não se trata, contudo, de simplesmente abandonar a discussão. O posicionamento aqui é o da constante desconfiança, tanto das pretensões estatizantes quanto daquelas oriundas de um "suposto" livre mercado, que tantas desigualdades e injustiças têm acarretado. Seguindo o pensamento foucaultiano e deleuze-guattariano, acreditamos na necessidade de se pensar para além das racionalidades políticas vigentes, uma tarefa demasiadamente complexa.

Dessa perspectiva e tendo em vista certo esgotamento das análises macropolíticas, que em geral operam por meio de modelos fixos, uma perspectiva que, a nosso ver, parece fecunda, é a concepção de "micropolítica" (DELEUZE; GUATTARI, 1996). Embora acoplada e coextensiva à macropolítica, a micropolítica apresenta relações distintas e implica em uma crítica à naturalização das instituições e, ainda, alude à criação e à formação dos desejos. Busca, portanto, operar no detalhe, nas percepções e afecções.

\footnotetext{
${ }^{3}$ AGAMBEN, Giorgio. A política da profanação. Entrevista concedida à Folha de São Paulo em 18.09.2005. Disponível em: 〈http://www1.folha.uol.com.br/fsp/mais/fs1809200505.htm〉.

${ }^{4}$ Na passagem do século XVIII para o século XIX, o diretor da escola militar de Berlim, general Carl Von Clausewitz, associou a política à guerra, através da seguinte frase: "a guerra é a continuação da política por outros meios".
}

\section{POLÊM!CA $\mid$ LABORE}




\section{Considerações finais}

Ao longo da trilogia Matrix, o mundo considerado real e o simulacro imbricam-se mutuamente. O desfecho da ficção cinematográfica torna praticamente impossível distinguilos, ou seja, não é possível determinar com precisão onde termina um (ficção) e inicia-se outro (realidade). Merece ser ressalvado, ainda, que em diversos momentos da trama, é por meio de ações efetuadas no mundo virtual que se pretende aceder à realidade. Uma construção, portanto. Desse ângulo, qual é, afinal, a similitude da trilogia com o campo discursivo aqui problematizado?

Ora, o pós-estruturalismo parte justamente da ideia de que a realidade é uma construção social, produzida pela linguagem, destarte, nada mais do que uma ficção. Ficção não no sentido de falso, longe disso, mas relativo à construção, à fabricação. Em suma, ao questionar radicalmente determinadas enunciações tomadas como verdadeiras, o pósestruturalismo não as nega, tão somente interroga a pretensão à verdade absoluta.

Se porventura nos indagarem se é possível questionar as verdades e fundamentos do próprio pós-estruturalismo, em coerência com essa perspectiva, prontamente diríamos que sim, entretanto, enfatizamos aqui que os pressupostos desse paradigma não são os mesmos da ciência clássica e, por conseguinte, não se almeja provar nada, pois operamos em uma perspectiva ou, ao menos, uma tentativa de problematizar, de manter uma atitude crítica sobre o presente. O ônus da prova, portanto, cabe aos "realistas" científicos.

Então, nas trilhas do pensamento pós-estruturalista, procuramos advertir para o duplo risco da adoção de uma posição totalizante ou, ao contrário, de uma atitude relativista em relação ao conhecimento, no sentido de "vale qualquer coisa", ignorando, assim, os efeitos e eventuais positividades de determinado saber ou saberes na explicação de fenômenos e materialidades específicas.

Certamente, o pensamento racional tem seu grau de importância, produz efeitos de verdade e de realidade, contudo, ao tomar determinada racionalidade como incontestável, corre-se o risco de tolher o pensamento e, ainda, adotar uma postura acrítica, tendo em vista que devido à suposta exatidão, não caberia questionamentos. Ademais, a razão não é transcendental, pois está ancorada historicamente, é uma construção política provisória e dependente do sensível, dos sentimentos.

\section{POLÊM!CA $\mid$ LABORE}


Quanto às racionalidades políticas, apesar das singularidades, ao que parece, tanto os governos enquadrados como de direita, quanto àqueles caracterizados como de esquerda, são regidos atualmente pela via econômica, em seu formato neoliberal.

Tendo em vista os efeitos nefastos de tal subserviência, urge que novas possibilidades possam ser inventadas e experimentadas, distantes daquelas direcionadas única e exclusivamente à acumulação do capital, cujo sujeito correspondente é o homo æeconomicus, aquele que adere às demandas do mercado econômico, um "empreendedor de si mesmo" (FOUCAULT, 2008).

Por fim, tomando o devido cuidado com relação às generalizações epistemológicas, não nos interessa tanto aqui o enquadramento sob o prefixo de pós a algo ou a alguém, como se isso por si só pudesse explicar "qualquer coisa", mas da possibilidade da adoção de uma postura que consiste em deslocarmos nosso olhar criticamente aos discursos vigentes na época contemporânea, independentemente de como ela seja classificada. Certamente, tarefa nada trivial.

\section{Referências}

AGAMBEN, Giorgio. A política da profanação. Entrevista concedida à Folha de São Paulo em 18.09.2005. Disponível em: <http://www1.folha.uol.com.br/fsp/mais/fs1809200505.htm>. Acesso em: 30/11/2016.

AGAMBEN, Giorgio. O que é o contemporâneo? e outros ensaios. Chapecó: Argos, 2009.

AVELINO, Nildo. Foucault e a racionalidade (neo)liberal. Revista Brasileira de Ciência Política, n. 21. p. 229286, set./dez. 2016.

CONNOR, Steven. Cultura pós-moderna. São Paulo: Loyola, 1996.

DELEUZE, Gilles. Entrevista a Claire Parnet. O que é ser de esquerda? 1989. Disponível em: $\langle$ https://www.youtube.com/watch?v=AF9EUmkkqx0>. Acesso em 10/10/2016.

DELEUZE, Gilles; GUATTARI, Félix. O que é a Filosofia. Rio de Janeiro: Editora 34, 1992.

DELEUZE, Gilles; GUATTARI, Félix. Mil platôs - capitalismo e esquizofrenia, vol. 3. Rio de Janeiro: Ed. 34, 1996.

FOUCAULT, Michel. As palavras e as coisas: uma arqueologia das ciências humanas. 8. ed. São Paulo: Martins Fontes, 2000.

FOUCAULT, Michel. Em defesa da sociedade. São Paulo, Martins Fontes, 2002.

FOUCAULT, Michel. A ética do cuidado de si como prática de liberdade. In: . Ética, política, sexualidade. Ditos e escritos V. Rio de Janeiro: Forense Universitária, 2004. p. 264-287.

FOUCAULT, Michel. O que são as Luzes. In: FOUCAULT, Michel. Arqueologia das ciências e história dos sistemas de pensamento. Ditos e escritos II. Rio de Janeiro: Forense Universitária, 2005. p. 335-351.

\section{POLÊM!CA $\mid$ LABORE}


FOUCAULT, Michel. Nascimento da biopolítica: curso dado no Collège de France (1978-1979). São Paulo: Martins Fontes, 2008.

GALLO, Silvio. Deleuze e a Educação. Belo Horizonte: Autêntica, 2013.

GROS, Frédéric. Situação do curso. In: FOUCAULT, Michel. O governo de si e dos outros: curso no Collège de France (1982-1983). São Paulo: Martins Fontes, 2010. p. 341-356.

HALL, Stuart. A centralidade da cultura: notas sobre as revoluções culturais do nosso tempo. Educação \& Realidade, Porto Alegre, v. 22, n. 2, p. 15-46, jul./dez. 1997.

HICKS, Stephen. Explicando o Pós-Modernismo: Ceticismo e socialismo - de Rousseau a Foucault. São Paulo: Callis, 2011.

LYOTARD, Jean-François. A condição pós-moderna. 12. ed. Rio de Janeiro: José Olympio, 2009.

Matrix (Filme). Direção: Lana Wachowski, Andy Wachowski, Produção: Joe Silver. Warner Bros, 1999.

Matrix Reloaded (Filme). Direção: Lana Wachowski, Andy Wachowski, Produção: Joe Silver. Warner Bros, 2003.

Matrix Revolutions (Filme). Direção: Lana Wachowski, Andy Wachowski, Produção: Joe Silver. Warner Bros, 2003.

Modernidade Revolutions (Documentário). 2017. Disponível em:

$<$ https://www.youtube.com/watch?v=CVeL5EwI8YU>. Acesso em 01/02/2017.

PETERS, Michael. Pós-Estruturalismo e Filosofia da Diferença. Belo Horizonte: Autêntica, 2000.

SANCHOTENE, Virgínia Crivellaro. A impossibilidade de permanência: conversas com Foucault e Deleuze. Porto Alegre: Cultura e Arte, 2015.

SILVA, Tomaz Tadeu da. Monstros, ciborgues e clones: os fantasmas da pedagogia crítica. In: (Org.). Pedagogia dos monstros: os prazeres e os perigos da confusão de fronteiras. Belo Horizonte: Autêntica, 2000. p. 11-22.

VEIGA-NETO, Alfredo. Um debate (im)possível. 1996. Disponível em:

<http://www.michelfoucault.com.br/files/Um\%20debate\%20im-poss\%C3\%ADvel.pdf.>. Acesso em: 03/09/2016.

WILLIAMS, James. Pós-Estruturalismo. Petrópolis: Vozes, 2012.

Recebido em: 04/02/2017

Aceito em: 10/08/2017

\section{POLÊM!CA $\mid$ LABORE}

Polêmica - Revista Eletrônica da Uerj - Rua São Francisco Xavier, 524, $1^{\circ}$ andar bloco D, sl.1001 • Tels.: +55 21 2334-4088/4087 • http://www.e-publicacoes.uerj.br/index.php/polemica/index http://www.labore.uerj.br • laboreuerj@yahoo.com.br 